\section{Severe depression with Cotard's phenomenon: treatment of a capacitated patient within the United Kingdom's Mental Health Act 2007}

\author{
Faraz Mughal, Simon B. Menezes \\ The Oleaster, National Centre for Mental \\ Health, Birmingham, UK
}

\begin{abstract}
Treatment of Cotard's syndrome with electroconvulsive therapy (ECT) has been seen to be an effective treatment option when pharmacological options are not successful. Recent changes in the Mental Health Act 2007 used within the United Kingdom has resulted in clinicians unable to prescribe treatment for patients who have capacity but are not providing consent for treatment. We report a case of a patient in the UK with Cotard's phenomenon and severe depression, where the only effective treatment of ECT was restricted due to changes in mental health law. The role of maintenance ECT as well as the ethical dilemma faced is discussed.
\end{abstract}

\section{Introduction}

Cotard's syndrome is a rare psychiatric disorder characterised by nihilistic delusions concerning one's own body. ${ }^{1}$ Described in 1880 by Jules Cotard, a French psychiatrist, patients typically believe they are dead or their bodily organs and limbs are rotting and disintegrating. ${ }^{2}$ In accordance with the Mental Health Act (MHA) legislation, for a patient who is detained under section 3 of the MHA 2007 and does not consent to treatment, where the responsible consultant considers treatment necessary, the Mental Health Act Commission must be contacted and the advice of a Second Opinion Appointed Doctor (SOAD) must be sought. A detained patient, who declines to give consent, cannot be given electroconvulsive therapy (ECT) unless the treatment is immediately necessary to save the patient's life or to prevent an immediate deterioration in their condition. Treatment of Cotard's syndrome secondary to an underlying mood disorder with ECT has been observed to be extremely effective. ${ }^{1}$ We report the case of a female patient who has a long history of somatisation presenting with depression and Cotard's phenomenon; highlighting an ethical dilemma of treatment with ECT within the United Kingdom's MHA.

\section{Case Report}

The patient is a 59 year old Caucasian female who lives alone in a council flat and has been known to mental health services for depression with somatic features. She presented to The Oleaster via the Home Treatment Team with worsening symptoms of somatisation and a loss of mobility. These symptoms began over twenty years ago where the patient described severe back and leg pain associated with cramping, paraesthesia, paresis and anergy. She felt this was as a result of a spinal injury she sustained while giving birth to her son. A magnetic resonance image of her spine only revealed disc degeneration. Prior to 2003 the patient had 14 admissions to hospital for these symptoms. Her mental health deteriorated over the days preceding admission and this manifested itself by hopelessness, despair and suicidal ideation. She felt she was a rotting corpse and expressed the wish of wanting to die. There were no current or previous attempts to commit suicide. She was low in mood and suffered from anhedonia. The patient displayed hostile behaviour. She also experienced reduced concentration, early morning awakening and a suppressed appetite. Furthermore, she was unable to shower because of the pain in her legs and consequently her personal hygiene deteriorated. The patient explained that the blood circulation to her legs was compromised therefore resulting in her legs rotting and falling off. In her opinion, she felt she had always been misdiagnosed and was pre-occupied about this. She asked why she was not in a nursing home as my legs are not working, rather than a mental health hospital.

The patient also suffered from rumination, constantly focusing on her back and leg pain in addition to conveying somatic delusions.

She had previously been discharged from inpatient services only two months prior to this admission. During her last inpatient stay, she was detained under Section 3 of the MHA 2007. Following initial treatment with antipsychotic and antidepressant medication the patient's mental state did not improve. She was therefore offered ECT and after 2 sessions she refused to have further courses of ECT. The patient at this time appealed against her detention and upon assessment appeared to have capacity. A SOAD was sought to review her capacity status. The SOAD concluded that the patient had capacity and ECT was therefore not viable and consequently it was withdrawn. The patient was subsequently discharged on a community treatment order with follow up in the community.

Prior to this informal admission, the patient had been functioning well in the community, no longer pre-occupied with her legs and suc-
Correspondence: Faraz Mughal, Department of Dermatology, Queen Elizabeth Hospital. University Hospital Birmingham, Edgbaston, Birmingham, B15 2TH, England, United Kingdom. Tel. +44.07976356209

E-mail: farazm@doctors.org.uk

Key words: Cotard's syndrome, depression, electroconvulsive therapy, mental health act, capacity.

Contributions: FM, undertook the analysis of the case, drafted, revised and edited the article, final approval of the version to be published was granted; SBM, design and critical revision of the article; final approval of the version to be published was granted.

Conflict of interest: the authors declare no potential conflict of interests.

Received for publication: 30 September 2011.

Revision received: 10 January 2013.

Accepted for publication: 30 January 2013.

This work is licensed under a Creative Commons Attribution NonCommercial 3.0 License (CC BYNC 3.0).

(C)Copyright F. Mughal and S.B. Menezes, 2013

Licensee PAGEPress, Italy

Mental Illness 2013; 5:e3

doi:10.4081/mi.2013.e3

cessfully undertaking her activities of daily living. Her marked progress in the community resulted in her Community Psychiatrist reducing the doses of her antidepressant and antipsychotic medication. This reduction in medication exacerbated a relapse of her delusional beliefs.

She has a history of hypertension and currently adheres to a depot pipothiazine injection every two weeks and duloxetine. There is no family history of psychiatric illness. The patient was brought up by her mother and stepfather, performing well at school and worked as a legal secretary until the birth of her first child. She was married for 18 years, however, is now divorced and attributes this to the problem with my legs. The patient has a 20 year history of smoking pack year history and previously consumed large quantities of alcohol, however has been abstinent for 1 year. She has never used illicit drugs. There is no forensic history and she independently resides in a council flat, receiving benefits with regular support from her son.

Upon examination, the patient was dressed in appropriate clothing, however appeared dishevelled and unkempt. She was anxious, rubbing her legs with her hands, and pacing the room. She made poor eye contact, making it difficult to establish a robust doctor-patient rapport. There was no psychomotor retarda- 
tion. Her speech was normal and she exhibited biological and cognitive features of depression. There was presence of nihilistic delusions as the patient felt her legs were rotting, however, there were no delusions of poverty or guilt. There was no evidence of hallucinations. Cognition was not affected, however, the patient had no insight. She claimed there was nothing wrong with her mental health, attributing all her symptoms to a physical aetiology. The patient's physical examination was unremarkable and her full blood count, urea and electrolytes and thyroid function tests were normal.

The patient was diagnosed with severe depression according to ICD-10, associated with Cotard's phenomenon. Her medication was readjusted to her previous dose in which her mental state was stable. Initially, during the admission, the patient kept a low profile, minimally interacting with staff and patients. On multiple occasions she fell to the floor, unable to move, stating that she cannot walk as her legs have fallen off. She had very poor dietary and fluid intake and showed evidence of severe weight loss. ECT was explained and offered to the patient in which the patient agreed to consent for therapy. She also requested physiotherapy as she felt this helped with her back pain in the past. Olanzapine was soon added and physiotherapy was discontinued as it was felt this was perpetuating her delusional beliefs. She continued on ECT, antidepressant and antipsychotic medication. Four weeks later she was reported to be much brighter in herself. Her insight improved with an understanding that there was an element of mental illness, however she still felt this was secondary to physical causes. The pipothiazine depot injection was stopped. After a course of twelve ECTs, the patient was eating and sleeping well, attending to her personal hygiene, her mood was subjectively and objectively euthymic and her nihilistic delusions had resolved. She had no suicidal or homicidal ideations and therefore was discharged from inpatient services.

She has been followed up by the Community Mental Health team and agreed to have maintenance ECT. The patient has been undertaking her daily activities, showing no signs of depression and the interval between ECT sessions is soon to be increased.

\section{Discussion}

A successful therapeutic outcome was reached because the patient consented to ECT. This is in contrast to the patient's previous admission, where she was detained under Section 3 of the MHA 2007, capacitated, and not consenting to ECT. In light of previous admissions and a relapse in the community, maintenance ECT was prescribed and has thus far resulted in complete remission of her mental illness.

There is only one case reported where maintenance ECT in Cotard's syndrome has been used. ${ }^{3-5}$ Maintenance ECT is said to be underused and insufficiently studied, despite positive experience in severe mood disorders and for prevention of relapse. ${ }^{6}$ The association of Cotard's syndrome with severe depression has been recognised and this report contributes to the current evidence base. This case demonstrates that Cotard's phenomenon occurs in severe depression and while the role of ECT in Cotard's syndrome is already well established, maintenance ECT has a role in the management of Cotard's syndrome. ${ }^{1}$

The case also highlights that a capacitated but non-consenting patient cannot be given
ECT, even if the patient is detained under the MHA 2007, which is an amendment of the MHA 1983. Furthermore, this is in keeping with the Mental Capacity Act 2005; but there are some ethical dilemmas for the treating doctor. In our case, we had to discharge the patient and wait until such a time, where she consented for ECT and with treatment, subsequently improved.

\section{References}

1. Debruyne H, Portzky M, Van den Eynde F, Audenaert K. Cotard's syndrome: a review. Curr Psychiatry Rep 2009;11:197-202.

2. Caliyurt 0, Vardar E, Tuglu C. Cotard's syndrome with schizophreniform disorder can be successfully treated with electroconvulsive therapy: case report. Psychiatry Neurosci 2004;29:138-41.

3. Mahgoub A, Hossain A. Cotard's syndrome and electroconvulsive therapy. Psychiatr Serv 2004;55:1319.

4. Petracca G, Migliorelli R, Vazquez S, Starkstein SE. SPECT findings before and after ECT in a patient with major depression and Cotard's syndrome. J Neuropsychiatry Clin Neurosci 1995;7:5057.

5. Hagen S, Voss SH. [Cotard's syndrome in depression and maintenance electroconvulsive therapy.] Ugeskr Laeger 2002;164:3452-3. [Article in Danish].

6. Petrides G, Tobias KG, Kellner $\mathrm{CH}$, Rudorfer MV. Continuation and maintenance ECT for mood disorders; review of the literature. Neuropsychobiology 2011;64:129-40. 